\title{
Feasibility of Converting Russian Icebreaker Reactors from HEU to LEU Fuel
}

\author{
Anatoli C. Diakov, 'Alexander M. Dmitriev, ${ }^{2}$ Jungmin Kang, ${ }^{3}$ \\ Alexey M. Shuvayev, ${ }^{1}$ and Frank N. von Hippel ${ }^{4}$ \\ ${ }^{1}$ Center for Arm Control, Moscow Institute of Physics and Technology, Dolgoprudny, \\ Moscow Region, Russia \\ ${ }^{2}$ Scientific \& Engineering Center on Nuclear and Radiation Safety, Moscow, Russia \\ ${ }^{3}$ Seoul, Republic of Korea \\ ${ }^{4}$ Program on Science and Global Security, Princeton University, Princeton, NJ, USA
}

A considerable amount of experience has been accumulated in converting compact research reactors from highly-enriched uranium (HEU) to low-enriched uranium (LEU). Although the details of naval-reactor design are closely held military secrets, during the Gorbachev period, the Soviet Union supplied the Norwegian government with some basic data, including the dimensions and ${ }^{235} \mathrm{U}$ content of the core of the HEU fueled KLT-40 reactor used in some Russian nuclear-powered icebreakers. A group of Norwegian analysts used this information to develop a simple model of the KLT-40 core. We have calculated the neutronics behaviors of variants of these core models as a function of ${ }^{235} \mathrm{U}$ burnup and conclude that the reactors could be fueled with LEU without loss of core life. We also show that simplified infinite-core calculations can be used for such studies.

\section{INTRODUCTION}

The use of high-enriched uranium (HEU) in reactor fuel creates dangers of theft or diversion of the HEU to weapons use. As a result, since 1978, there has been a major international effort to convert HEU-fueled research and test reactors to low-enriched uranium (LEU containing less than $20 \%{ }^{235} \mathrm{U}$ ), which is not considered a directly weapon-useable material. ${ }^{1}$ No similar official effort has yet been mounted to convert ship and submarine-propulsion reactors. ${ }^{2}$ Since more design information is available about the core of the KLT-40 reactor used on some Russian nuclear-powered icebreakers than for the reactors used to

Received 4 April 2005; accepted 26 December 2005.

Address correspondence to Anatoli C. Diakov, Center for Arms Control, Moscow Institute of Physics and Technology, 9 Institutski Per., Dolgoprudny, Moscow Region 141700, Russia. E-mail: das@armscontrol.ru 


\section{Diakov et al.}

propel navy ships, we have carried out a preliminary study on it and conclude that it should be possible to convert it to low-enriched uranium (LEU) fuel without reducing the core life.

\section{REACTOR CORE DESIGN}

Some information on the reactor core design of the Russian transport/icebreaker Sevmorput was provided by the Soviet government to the Norwegian government in connection with a port visit to Troms $\emptyset$ in 1990 (see Table 1). In some cases, however, different information is available from other sources. Most notably, a publication by the Norwegian Bellona Foundation cites a communication from the Murmansk Shipping Company, the operator of the nuclear-powered icebreakers, to the effect that the enrichment of the icebreaker fuel is currently $30-40 \%$, not $90 \% .^{3}$

The Sevmorput safety report also suggests that the fuel assemblies are in channels that keep the cooling water that flows through the fuel assemblies separate from the water between the fuel assemblies. ${ }^{4}$ This arrangement was used in the propulsion reactors of the Lenin, Russia's first nuclear-powered icebreaker. It has the advantage that the water between the fuel assemblies can be kept at a relative constant temperature, reducing the effect on the reactivity when cold cooling water is pumped into the fuel assemblies when a pump is restarted. ${ }^{5}$

Table 1: Data on the design of the Sevmorput KLT40 reactor core provided by the Russian to the Norwegian Government. ${ }^{i}$

\begin{tabular}{ll} 
Power & 135 thermal megawatts $(\mathrm{MWt})$ \\
Mass of ${ }^{235} \mathrm{U}$ & $150.7 \mathrm{~kg}$ in 90 -percent enriched \\
& uranium in uranium-zirconium alloy \\
Active core height & $\mathrm{H}_{0}=1.00$ meters \\
Radius & $\mathrm{R}_{0}=0.606$ meters \\
Heat transfer area of the fuel & $233 \mathrm{~m}^{2}$ \\
Fuel assemblies & $241: 6 \mathrm{~cm}$ in diameter in a triangular \\
& lattice with $7.2 \mathrm{~cm}$ center-to-center \\
& spacing \\
Control & 19 control rods in each of 16 fuel \\
Neutron absorbing rods & assemblies \\
Neutron source for startup & Natural gadolinium \\
Fuel rod outer & BeO (gamma absorption produces \\
diameter/center-to-center spacing & neutrons) \\
Peak/average power & $0.58 \mathrm{~cm} / 0.7 \mathrm{~cm}$ \\
Maximum fuel-surface temperature & radial $=1.27 ;$ axial = 2.07 \\
Design operating period & $335^{\circ} \mathrm{C}$ \\
& 10,000 equivalent full-power hours (417 \\
& days) \\
\hline
\end{tabular}

iInformation of Safety of Icebreaker-Transport Light/Containership with Nuclear Propulsion Plant Sevmorput (1982). 


\section{NORWEGIAN MODEL}

Using the information in Table 1, a group of Norwegian analysts developed a notional core design. ${ }^{6}$ They assumed a triangular close-packed array of fuel assemblies, each surrounded with a cylindrical zirconium shroud of thickness $0.15 \mathrm{~cm}$. A triangular close-packed array of cylindrical fuel rods within each assembly provides space for 55 fuel rods (see Figure 1). The central position in each assembly was assumed to be kept empty for insertion of a photo-neutron source to help initiate the chain reaction. Six positions in the 12-element circle around the center element were assigned to burnable $\mathrm{Gd}_{2} \mathrm{O}_{3}$ neutron absorber elements. The fuel cladding was assumed to be $0.06 \mathrm{~cm}$-thick zirconium and the fuel "meat" to be made up of zirconium-uranium alloy containing 4.5 grams of uranium per cubic centimeter (gmU/cc) in the form of a hollow cylinder with outer and inner radii 0.23 and $0.21 \mathrm{~cm}$ respectively. The Norwegian group showed that this design could indeed generate $135 \mathrm{MWt}$ for 417 days and still have a substantial margin of excess reactivity remaining $\left(\mathrm{k}_{\text {eff }}>1.2\right)$. It also found that increasing the coolant temperature decreases the reactivity-an important safety feature for water-cooled reactors. ${ }^{7}$

As Figure 1 shows, the water-filled space between the fuel assemblies is larger than between the fuel rods within the assemblies. As a result, the

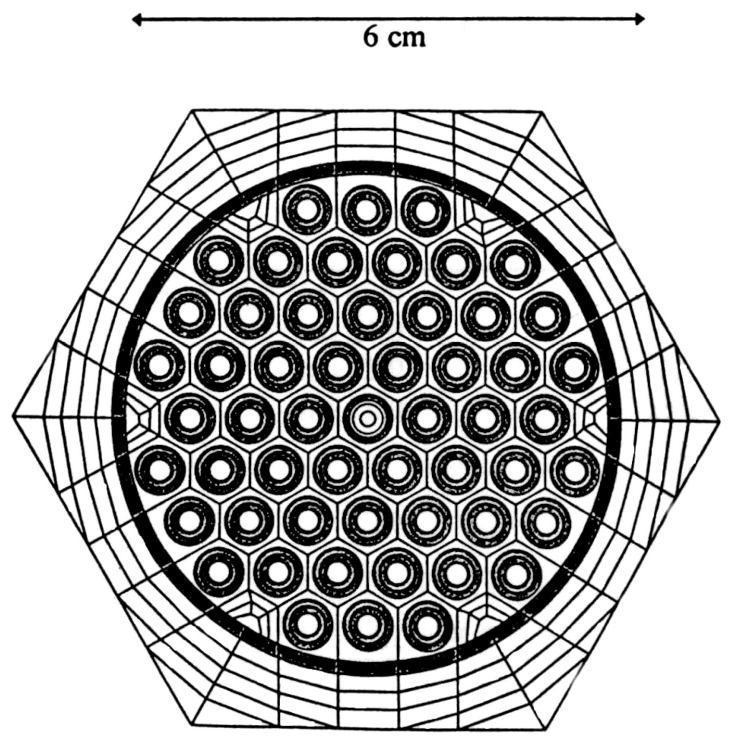

Figure 1: Cross-section of the Norwegian model of a Sevmorput fuel assembly. The hexagonal pattern of lines between the fuel rods does not represent physical structure. It has been added to make the hexagonal arrangement apparent. Similarly, the hexagon around the cylindrical shroud shows the amount of water outside associated with each fuel assembly.

${ }^{i}$ Criticality Calculations on Russian Ship Reactors and Spent Nuclear Fuel, op cit, Fig. 5.2. 
neutrons coming into the fuel assemblies from the outside will have had more collisions with water molecules and will have lower velocities on average than neutrons inside the fuel assemblies. Because the probability of a fission resulting from a neutron interaction with a fissile nucleus grows with the inverse of the neutron velocity, the rate of fission in the outer fuel rods will be higher than in the inner rods. This could be rectified by decreasing the ${ }^{235} \mathrm{U}$ density (i.e., the uranium density or the enrichment of the uranium) in the outer ring of fuel rods and increasing that of the inner two rings relative to the average density or enrichment in the second ring from the outside. ${ }^{8}$ In fact, it is believed that the cores of at least Russia's third-generation submarine reactors contain fuel rods with a range of enrichments. ${ }^{9}$

If the hollow fuel rods assumed in the base-case Norwegian model were replaced with solid fuel rods, the volume of the fuel "meat" would be increased sufficiently so that the $90 \%$ enriched weapon-grade uranium (WgU) could be replaced by $20 \%$ enriched uranium with the same $4.5 \mathrm{gmU} / \mathrm{cc}$ density while increasing the ${ }^{235} \mathrm{U}$ loading by a factor of $1.13 .{ }^{10}$ We name this variant of the Norwegian model the "solid-fuel Norwegian Model."11

A density of $4.5 \mathrm{gmU} / \mathrm{cc}$ appears potentially feasible. The Bochvar Research Institute for Inorganic Materials in Moscow, which has the responsibility of developing new fuels for Russian nuclear reactors, has developed candidate fuels for the KLT-40 with high thermal conductivities and uranium densities up to 10 gmU/cc. ${ }^{12}$ In its Rubis class of small attack submarines, France's Navy already uses 7-percent enriched LEU “caramel” fuel (plates of $\mathrm{UO}_{2}$ wafers coated with zircalloy) with an average uranium density in the fuel "meat" of $8.7 \mathrm{gmU} / \mathrm{cc}$ fuel. ${ }^{13}$

One obvious issue with solid fuel rods is that the center-line temperatures would be higher than in the hollow-core fuel assumed by the Norwegian group. The average power output from the fuel rods is about $12 \mathrm{kWt} / \mathrm{m}$ with the peak output in the center of the core at beginning of core life being about 2.6 times higher or about $30 \mathrm{kWt} / \mathrm{m}$. Tests by the Bochvar Institute group of the thermal conductivity of their LEU fuel-designs found acceptable centerline temperatures, however, for fuel rods with power outputs up to $46 \mathrm{kWt} / \mathrm{m} .{ }^{14}$

The assumed layout of the fuel assemblies in the core is shown in Figure 2.

\section{RUSSIAN MODEL}

An alternative model has been developed by the Russian coauthors of this paper. ${ }^{15}$ They assumed that the current enrichment of the icebreaker cores is 40\%-consistent with the Bellona Foundation report quoted previously. They also assumed only 37 spaces for rods per fuel assembly vs. 55 in the Norwegian model. Finally, they assumed a cruciform geometry for the fuel rods (see Figure 3a). This type of fuel is used in Russian research reactors that operate 


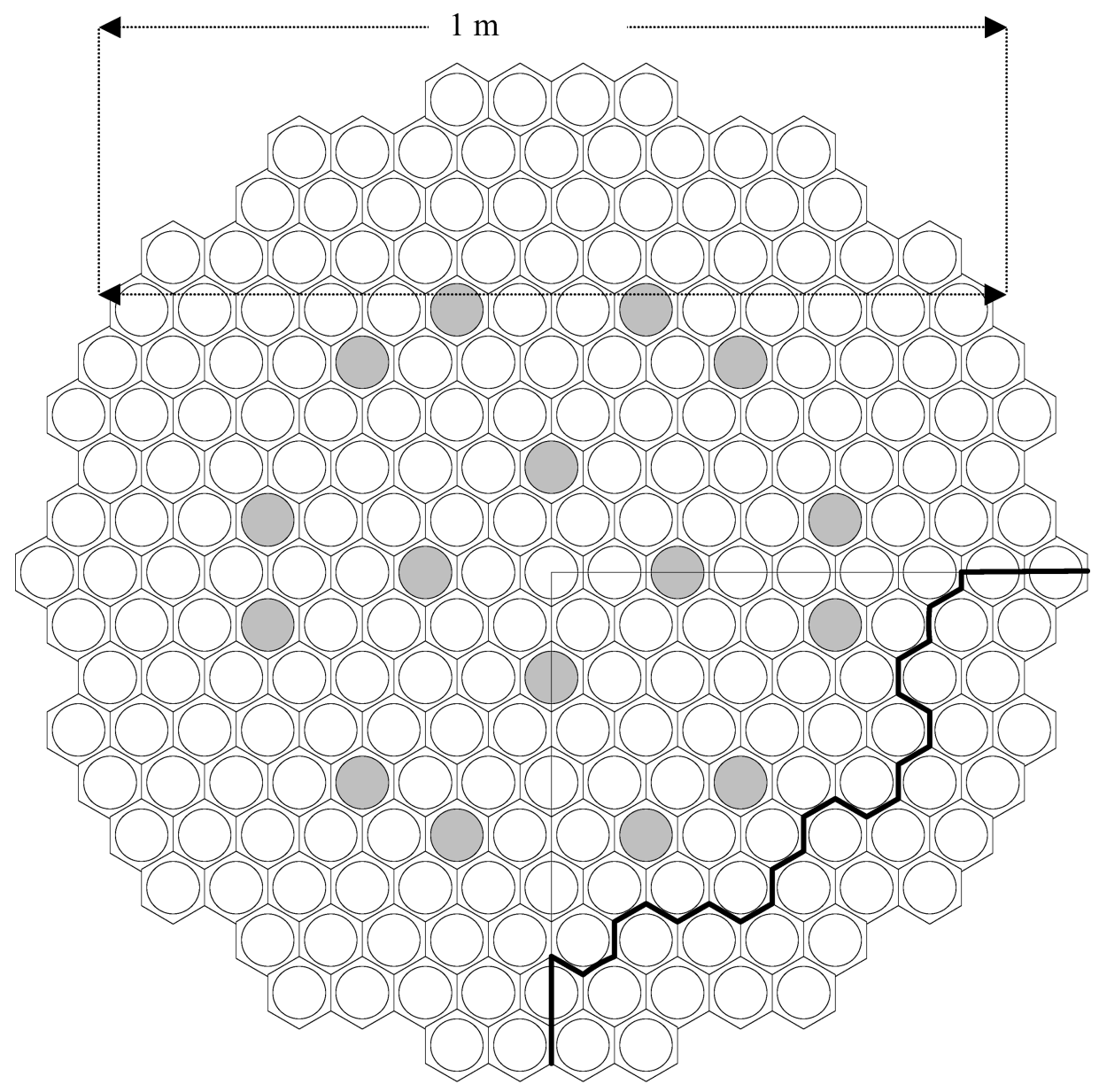

225 fuel assemblies that include 7 empty rod positions for $6 \mathrm{Gd}$ rods and a source rod

16 fuel assemblies that include 19 empty rod positions for control rods

Figure 2: Arrangement of fuel assemblies in the Norwegian model of the Sevmorput core design (horizontal cross section). The boundaries of the hexagons are mathematical, not physical. The darker fuel assemblies are assumed to contain spaces for 19 control rods each (the central position plus the two rings around it). One eighth of the core was modeled in the neutron-transport calculations: a 90 -degree radial wedge of the top half of the core. Making the internal radial surfaces of the one-eighth core neutron reflecting simulates the effect of the remainder of the core. The outer two layers of fuel assemblies plus the top and bottom $20 \mathrm{~cm}$ of the fuel rods were included in the outer zone in the 2-zone calculations. 


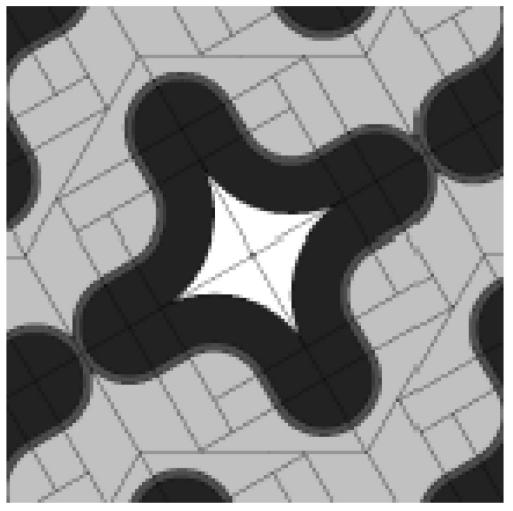

(a)

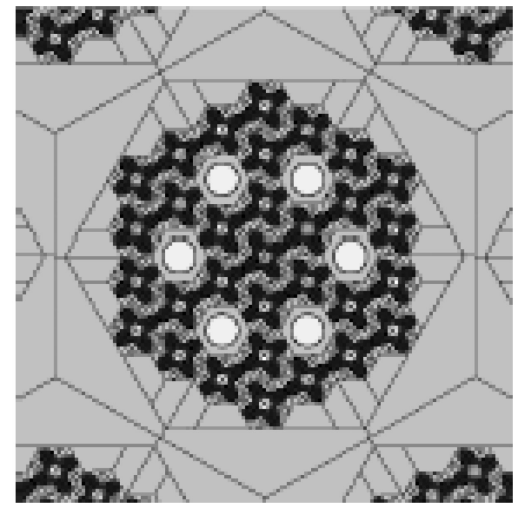

(b)

Figure 3: a) Cross section of Russian model fuel rod; b) Cross section of Russian model assembly (both for model 2).

with similar coolant temperatures to that in the Sevmorput reactor. ${ }^{16}$ The pins are formed by drawing a hollow cylinder through a die. This leaves an empty volume in the center where fission-product gases can accumulate. ${ }^{17}$ The cruciform shape is twisted into a spiral form which results in outer edges of neighboring fuel rods touching at a number of points along their length, making rod spacing hardware unnecessary. The cruciform shape also decreases the thickness of fuel meat for a given fuel volume and hence the temperature drop across the meat. In all cases, the cladding of the fuel rods and gadolinium pins is assumed to be $0.017 \mathrm{~cm}$-thick stainless steel.

Table 2 gives the core parameters assumed in four variants of the Russian model (we show only data that differs from that given in Table 1). Unlike

Table 2: Parameters for the Russian models.

\begin{tabular}{|c|c|c|c|c|}
\hline & Model no. 1 & Model no. 2 & Model no. 3 & Model no. 4 \\
\hline Core active height (m) & 0.9 & 0.9 & 0.9 & 0.9 \\
\hline Core radius $(m)$ & 0.45 & 0.6 & 0.6 & 0.6 \\
\hline \multicolumn{5}{|l|}{ Fuel assembly } \\
\hline diameter/spacing $(\mathrm{cm})$ & $4.2 / 5.4$ & $5 / 7.2$ & $5 / 7.2$ & $5 / 7.2$ \\
\hline Fuel pin spacing $(\mathrm{cm})$ & 0.7 & 0.81 & 0.81 & 0.81 \\
\hline Fuel pin max. dia. (cm) & 0.58 & 0.81 & 0.81 & 0.81 \\
\hline -fin thickness $(\mathrm{cm})$ & 0.23 & 0.23 & 0.15 & 0.23 \\
\hline -meat area $\left(\mathrm{cm}^{2}\right)$ & 0.140 & 0.221 & 0.146 & 0.221 \\
\hline \multicolumn{5}{|l|}{ Total densities ( $\mathrm{gm} / \mathrm{cc})$} \\
\hline$-40 \%$ enrichment & 6.13 & 4.86 & 5.97 & 4.69 \\
\hline$-20 \%$ enrichment (LEU) & 9.79 & 7.17 & 9.46 & 6.69 \\
\hline \multicolumn{5}{|l|}{ U densities $(\mathrm{gm} / \mathrm{cc})$} \\
\hline $\begin{array}{l}-40 \% \text { enrichment } \\
-20 \% \text { enrichment (LEU) }\end{array}$ & $\begin{array}{l}3.60\left(\mathrm{U}-\mathrm{Al}_{6.2}\right) \\
7.19\left(\mathrm{U}-\mathrm{Al}_{3}\right)\end{array}$ & $2.27\left(\mathrm{U}-\mathrm{Al}_{10}\right)$ & $3.44\left(\mathrm{U}-\mathrm{Al}_{6.5}\right)$ & 2.27 \\
\hline & & & & \\
\hline
\end{tabular}


our calculations with the Norwegian model, where the amount of ${ }^{235} \mathrm{U}$ in the 20-percent enriched core is assumed to be 13 percent higher than in the 90-percent core, in the Russian core, the quantity of ${ }^{235} \mathrm{U}$ is assumed to be the same in the 40-percent and 20-percent enriched cores. Model 1 is for a more compact core such as might be used in a submarine. ${ }^{18}$ As with the Norwegian model, six of the spaces in the fuel assembly are assumed to be occupied by neutron-absorbing gadolinium rods (see Figure $3 b){ }^{19}$

In one of the Russian models, the fuel meat was assumed to be $\mathrm{UO}_{2}$ particles dispersed in aluminum. In the other three, it was assumed to be uraniumaluminum alloy. As the atomic ratio of aluminum to uranium drops toward 4 , the fuel thermal conductivity drops to very low values. ${ }^{20}$ The meats of the higher-density fuels considered in the Russian models 1-3 would therefore have to be made of other materials such as those being considered by the Bochvar Institute (see above). LEU models 2 and 4 require similar uranium densities to those used in the solid-fuel Norwegian model.

\section{CALCULATED NEUTRON-MULTIPLICATION FACTORS, $k_{\text {eff }}$}

In order for a reactor to operate, the neutrons flowing within its core have to replace themselves by causing fissions as they are lost by absorption or leakage through its surface. The measure of this reproduction rate is the neutron-multiplication factor, $\mathrm{k}_{\mathrm{eff}}$. A reactor operating at steady power has $\mathrm{k}_{\mathrm{eff}}=1$. Neutron-absorbing "control rods" are included in the core design to allow the operator to compensate for changes in $\mathrm{k}_{\mathrm{eff}}$ due to changes in the cooling water temperature and concentrations of short-lived fission products, which depend upon the reactor power level. The $\mathrm{k}_{\mathrm{eff}}$ is adjusted by inserting the control rods deeper into the core or withdrawing them. All our calculations of $\mathrm{k}_{\text {eff }}$ below are for a core model in which the control rods are fully withdrawn. The values will therefore necessarily be greater than $1 .^{21}$

The $\mathrm{k}_{\text {eff }}$ of the core without control rods or other added neutron "absorbers" decreases steadily as the fissile ${ }^{235} \mathrm{U}$ in the fuel is consumed and then there is a large step increase in reactivity when the depleted fuel is replaced with fresh fuel. Rods of neutron-absorbing material are included in the fresh fuel assemblies to reduce these secular changes in reactivity. As the ${ }^{235} \mathrm{U}$ is consumed, reducing the core reactivity, so is the neutron absorber, which reduces its negative effect on the reactivity. In some cases which follow, we will estimate $\mathrm{k}_{\mathrm{eff}}$ in the absence of these "burnable neutron poisons" and will see the secular reduction of the reactivity of a fresh core as the ${ }^{235} \mathrm{U}$ is consumed. The value of the core neutron multiplication factor, $\mathrm{k}_{\mathrm{eff}}$ was calculated as a function of days of burnup at full power.

The calculations were done for a $90^{\circ}$ wedge of the top half of the core with the rest of the core represented by neutron-reflecting boundaries. The core is 
assumed to be in the center of a cylindrical pressure tank of water with a full height of 2.4 meters and a radius of 1 meter. The neutron-transport code $\mathrm{MCNP}^{22}$ was used to calculate $\mathrm{k}_{\mathrm{eff}}$ of the Sevmorput core using cross sections evaluated at a temperature of $295^{\circ} \mathrm{C}$ for the Norwegian model and $300^{\circ} \mathrm{C}$ for the Russian models. The ORIGEN2 $\operatorname{code}^{23}$ was used to calculate the depletion and buildup of isotopes in the fuel.

\section{Norwegian Model}

For the Norwegian model, the criticality calculations were done first with the volume-average burnup and then with two zones. In the 2 -zone calculations, the outer zone includes the top and bottom $20 \mathrm{~cm}$ of the core and the 102 outer assemblies shown in Figure 2. This accounts for 53 percent of the uranium in the core.

Figure $4 \mathrm{a}$ shows the values of $\mathrm{k}_{\text {eff }}$ calculated in the full-core, one-zone calculation for $90 \%$ enriched fuel with and without the gadolinium neutronabsorbing rods. ${ }^{24}$ With the absorbers, the reactivity is initially depressed. However, the gadolinium is consumed faster than the ${ }^{235} \mathrm{U}$ with the result that $\mathrm{k}_{\text {eff }}$ peaks at about 300 days before declining as the fissile material burns out. The initial drop in the reactivity at the beginning of operation is due to the buildup of fission products with large cross-sections for neutron absorption.

Figure $4 \mathrm{~b}$ compares the values of $\mathrm{k}_{\text {eff }}$ calculated with the $90 \%$ and $20 \%$ enriched uranium fuel in the absence of neutron-absorbing rods. It will be seen that, while the initial excess reactivity of the LEU core is lower than that of the HEU core, the reactivity at high burnups is greater because of the contribution of the plutonium bred in the added ${ }^{238} \mathrm{U}$. We found very little difference for the one- and two-zone calculations. We therefore do not show the 2-zone results here.
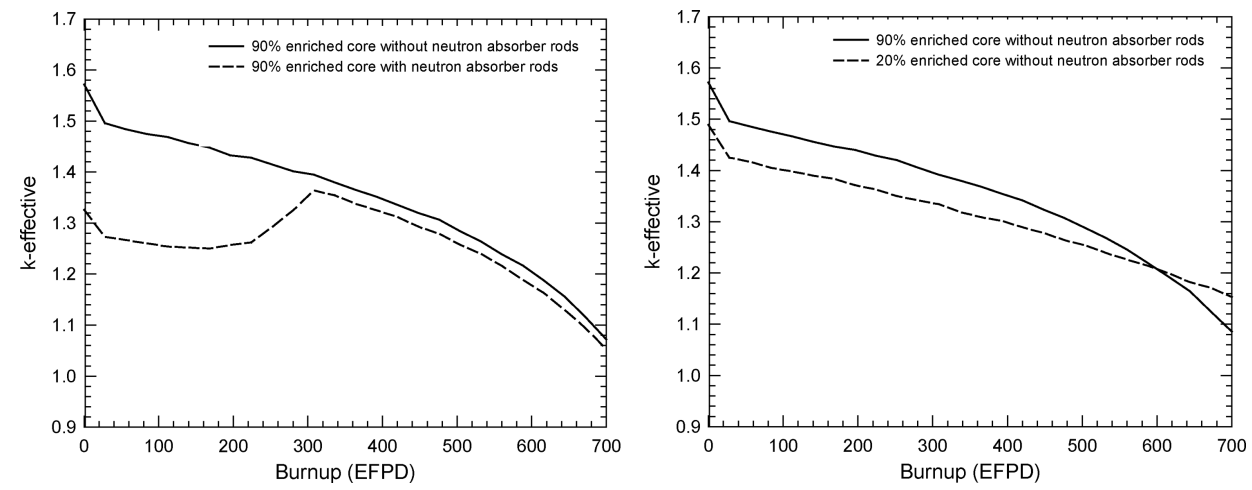

Figure 4: $K_{\text {eff }}$ of the Norwegian-core model: a) $90 \%-e n r i c h e d$ solid-core fuel with and without neutron absorber rods as a function of burnup; b) $90 \%$ and $20 \%$-enriched uranium without neutron absorbers. 


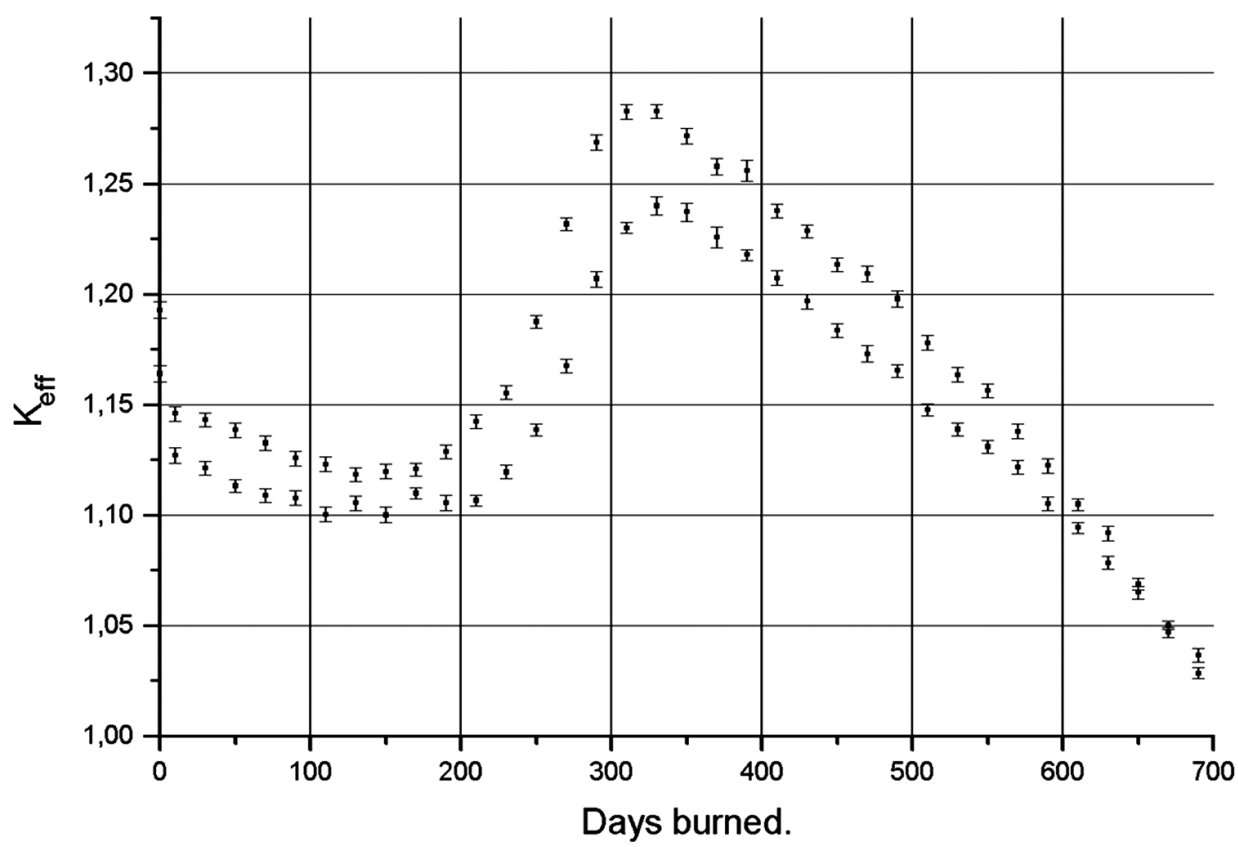

Figure 5: $K_{\text {eff }}$ for Russian Model 2 core. Curve above is for $40 \%$ enriched uranium. Curve below for $20 \%$.

\section{Russian Model}

Figure 5 shows $\mathrm{k}_{\text {eff }}$ burnout curves for Model 2 . The $\mathrm{k}_{\text {eff }}$ values for the $20 \%$ enrichment are slightly below those for the $40 \%$ enrichment case because of neutron absorption by the added ${ }^{238} \mathrm{U}$. (The quantity of ${ }^{235} \mathrm{U}$ in the core is the same in both cases.) However, once again, the gap closes at high burnup because of the greater amount of plutonium bred by neutron capture in ${ }^{238} \mathrm{U}$ in the LEU fuel.

Table 3 shows calculated results for $\mathrm{k}_{\mathrm{eff}}$ at beginning of core life and at 417 days for each model. It will be seen that, for the Russian models, the reactivity is

Table 3: Comparison of calculated $k_{\text {eff }}$ for the Sevmorput core with fresh fuel and at design burnup with high and low-enriched uranium.

\begin{tabular}{lllll}
\hline $\begin{array}{l}\text { Model } \downarrow \\
\text { Full-power days } \rightarrow\end{array}$ & \multicolumn{2}{c}{$\mathbf{c}$} & \multicolumn{2}{c}{$\mathbf{4 1 7}$} \\
\hline Norwegian Model fuel enrichment & $90 \%$ & $20 \%$ & $90 \%$ & $20 \%$ \\
-Full core (single zone) & 1.572 & 1.489 & 1.338 & 1.283 \\
-Full core (two zones) & 1.572 & 1.489 & 1.343 & 1.290 \\
Russian Models fuel enrichment & $40 \%$ & $20 \%$ & $40 \%$ & $20 \%$ \\
Model 1 & 1.07 & 1.05 & 1.13 & 1.08 \\
Model 2 & 1.15 & 1.13 & 1.23 & 1.20 \\
Model 3 & 1.13 & 1.10 & 1.25 & 1.22 \\
Model 4 & 1.12 & 1.10 & 1.23 & 1.19 \\
\hline
\end{tabular}


higher at 417 days than at beginning of fuel life because the decline in neutron poisoning has more than offset the effect of the consumption of ${ }^{235} \mathrm{U}$. The onestandard-deviation uncertainties on the values of $\mathrm{k}_{\text {eff }}$ are all less than $0.3 \%$.

In the Appendix, we show that much the same results can be obtained with simplified infinite core models.

\section{CONCLUSION}

Our results suggest that the Russian ice-breaker KLT-40 reactors can be fueled with LEU without decreasing the lifetime of the core if fuels with the uranium density assumed could operate to the burnup assumed. The LEU densities required by the Norwegian solid-core model and Russian Models 2 and 3 are about the same: $4.5 \mathrm{gmU} / \mathrm{cc}$. The uranium densities required by the Russian Models 1 and 4 are higher.

\section{APPENDIX: CALCULATIONS OF $\mathrm{K}_{\text {eff }}$ IN INFINITE-CORE APPROXIMATION}

In this appendix, we review first the formulae relating infinite and finite-core calculations of $\mathrm{k}_{\text {eff. }}$ Then we describe a set of infinite-core calculations built on models with single rods and fuel assemblies surrounded by neutron reflecting surfaces.

\section{Calculating Finite-Core from Infinite-Core Neutron-Multiplication Factors $^{25}$}

The standard nuclear-engineering text book formula relating the neutron multiplication constant for an infinite core $\mathrm{k}_{\text {inf }}$ to the $\mathrm{k}_{\text {eff }}$ for a finite core is

$$
\mathrm{k}_{\mathrm{eff}}=\mathrm{k}_{\mathrm{inf}} /\left[1+\mathrm{M}^{2} \mathrm{~B}^{2}\right] .
$$

The factor $\left[1+\mathrm{M}^{2} \mathrm{~B}^{2}\right]^{-1}$ is the "neutron non-leakage probability." That is it accounts for the loss of neutrons through the finite core's surface. The product $\mathrm{M}^{2} \mathrm{~B}^{2}$ is a measure of the importance of neutron leakage. $\mathrm{B}^{2}$, the "buckling," is the divergence of the gradient of the neutron fluence in the core and characterizes the flow of the neutrons toward the core surface. It has the dimensionality of inverse length squared and decreases as the size of the core increases. $\mathrm{M}^{2}$, the square of the "migration length," is one-sixth the mean-square distance between the creation and absorption points of neutrons in the core.

For a cylindrical core with effective height $H$ and radius $R$,

$$
\mathrm{B}^{2}=(2.405 / \mathrm{R})^{2}+(\pi / \mathrm{H})^{2} \text {. }
$$


Table A-1: Calculation of buckling from fluence distribution calculated by MCNP for 1-meter-thick infinite slab reactor with $0.7 \mathrm{~m}$ layers of water at top and bottom.

\begin{tabular}{ccc}
$\mathbf{z}$ (distance from mid-plane in $\mathbf{m})$ & Relative fluence $\left(\boldsymbol{\Phi} / \Phi_{\mathbf{0}}\right)$ & $\mathbf{B}=\operatorname{Cos}^{-1}\left(\boldsymbol{\Phi} / \Phi_{\mathbf{0}}\right) / \mathbf{z}$ \\
\hline $0.0-0.05$ & 1.000 & - \\
$0.05-0.15$ & 0.95 & 3.18 \\
$0.15-0.25$ & 0.86 & 2.68 \\
$0.25-0.35$ & 0.67 & 2.79 \\
$0.35-0.45$ & 0.47 & 2.70 \\
$0.45-0.50$ & 0.31 & 2.64 \\
\hline
\end{tabular}

The effective height and radius are larger than the geometric height $\mathrm{H}_{0}$ and radius $R_{0}$ of the physical core because of neutron reflection by the water surrounding the core. ( $\mathrm{H}_{0}=1 \mathrm{~m}$ and $\mathrm{R}_{0}=0.6 \mathrm{~m}$ for the Sevmorput reactor core.)

The magnitude of this effect can be seen for the infinite slab reactor with height $\mathrm{H}_{0}$. The fluence distribution for this reactor has the form

$$
\Phi=\Phi_{0} \operatorname{Cos}(\mathrm{Bz}) .
$$

In the absence of material above and below the reactor, the fluence would go to zero at the top of the bottom of the slab at $\mathrm{z}= \pm \mathrm{H}_{0} / 2$, giving $\mathrm{B}=\pi / \mathrm{H}_{0}$.

We have used MCNP to calculate the value of $B$ for a one-meter-thick infinite slab reactor with 0.7 -meter water layers above and below. Table A-1 shows the calculated neutron fluence relative to that at the center of the slab in layers an average of $0.01,0.2,0.3,0.4$ and 0.475 meters away from the center plane. It also shows the values of $B$ obtained by fitting the results in each bin to equation A-3. It will be seen that the best fit is for $\mathrm{B} \cdot 2.70 \mathrm{~m}^{-1}$ or $\mathrm{H}=\pi / \mathrm{B}=1.16 \mathrm{~m}$. This is roughly consistent with the well-known result that the presence of a water reflector increases the effective core height by an amount, ${ }^{26}$

$$
\mathrm{H}=\mathrm{H}_{0}+2 \delta, \quad \text { where } \delta \approx 0.097 \mathrm{~m} .
$$

The radius of the reactor is similarly increased by

$$
\mathrm{R}=\mathrm{R}_{0}+\delta .
$$

Using the value $\delta=0.08$ obtained from our calculation and substituting the resulting values for the Sevmorput core, $\mathrm{H}=1.16 \mathrm{~m}$ and $\mathrm{R}=0.68 \mathrm{~m}$, in A-2 gives $\mathrm{B}^{2}=21.1 \mathrm{~m}^{-2}$

Once $B^{2}$ is fixed for a slab reactor, $M^{2}$ may be calculated from equation $A-1$ if we calculate both $k_{\text {inf }}$ and $k_{\text {eff }}$ using MCNP. Inserting in equation A-1 the values obtained for the eight pairs of infinite core and reflected slab core calculations whose results are shown in Table A-2 gives an average neutron non leakage probability of $95.35 \%$ for the reflected slab reactor, i.e.,

$$
\left(1+\mathrm{M}^{2} \mathrm{~B}^{2}\right)^{-1}=\mathrm{k}_{\mathrm{eff}} / \mathrm{k}_{\mathrm{inf}}=0.9535 \text { for slab reactor, }
$$




\section{Diakov et al.}

Table A-2: Comparision of $k_{\text {eff }}$ for the solid-rod Norwegian model of the Sevmorput core without neutron absorbers obtained using: a) full-core calculations and b) eqn. A- 1 and $k_{\text {inf }}$ for reflected single assemblies and single rods.

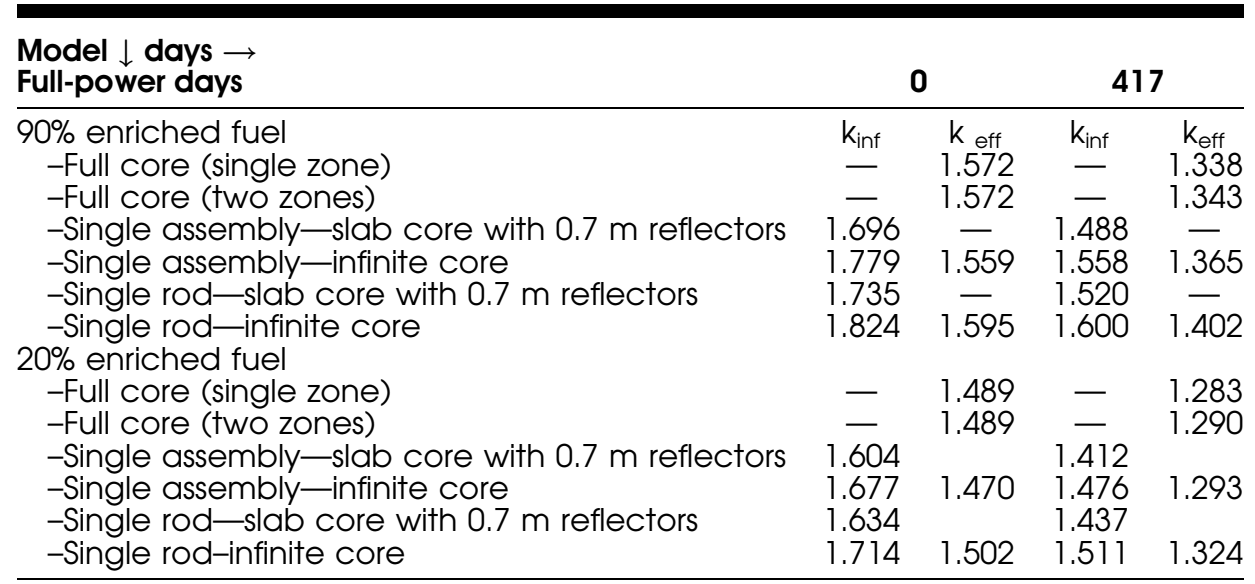

which yields $\mathrm{M}^{2}=0.00669 \mathrm{~m}^{2}$ and

$$
\left(1+\mathrm{M}^{2} \mathrm{~B}^{2}\right)^{-1}=0.876 \text { for the Sevmorput reactor. }
$$

We then can finally use this nonleakage probability to get an estimate of $\mathrm{k}_{\mathrm{eff}}$ for the finite reflected Sevmorput cylindrical reactor from the value of $\mathrm{k}_{\mathrm{inf}}$ determined for the infinite reactor based on a fully reflected single rod or single assembly: $\mathrm{k}_{\mathrm{eff}}=0.876 \mathrm{k}_{\mathrm{inf}}$.

\section{Calculations of $\mathrm{k}_{\text {inf }}$ for the Sevmorput core}

$\mathrm{K}_{\text {inf }}$ was estimated for infinite cores made up of arrays of both Sevmorput single rods and fuel assemblies. The single-rod and fuel-assembly models were based on the solid-fuel Norwegian core model.

In the infinite-core calculations, the computer calculates the neutron multiplication of a single rod or fuel assembly embedded in its share of the core water surrounded by a surface through which neutrons come at a rate equal to that at which they leave (see Figure 6). This is accomplished by making the surfaces surrounding the water perfect neutron "reflectors." Every time a neutron strikes the surface, it is assumed to bounce back elastically.

In the single-rod approximation, the core is assumed to be made up of an array of single fuel rods with a thickened cladding (outside radius $=0.268 \mathrm{~cm}$ ) to take into account the zirconium in the assembly shroud. The rods are assumed to be surrounded by water inside a neutron-reflecting cylinder with radius $0.51 \mathrm{~cm}$. In the single-assembly approximation, the assembly is placed 
a) Single rod

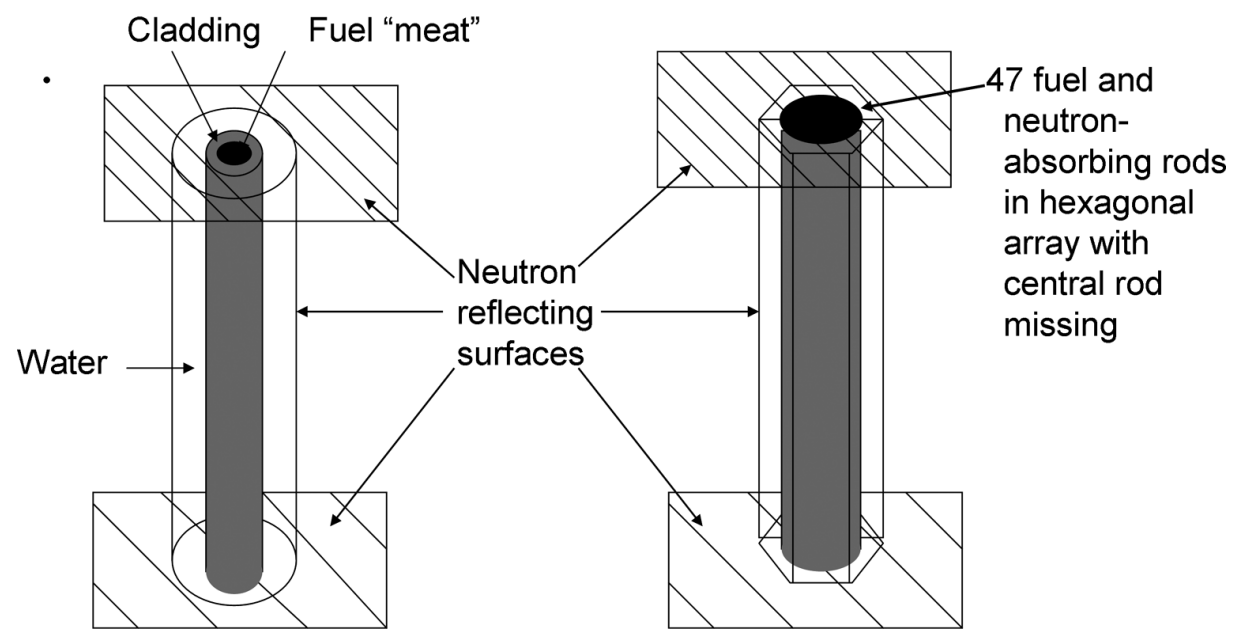

Figure 6: Infinite-core approximations: a) A single rod with its cladding thickened by its share of the assembly shroud material; b) A single fuel assembly is surrounded by its share of the in-core water. The rest of the core is simulated by surrounding the rod and water with a neutron-reflecting surface so that as many neutrons come into the volume as leave.

inside a cylinder of water with hexagonal cross-section and side-to-side width of $7.2 \mathrm{~cm}$.

\section{Infinite-Slab Core Calculations}

In the infinite-slab core calculations, the finite length of the fuel rods is taken into account. The fuel rods and assemblies are taken to be 0.5 meters long, i.e., half their actual length. Their bottoms are placed on a neutron-reflecting surface that represents the center plane of the core. Because the lower half of the core is below the plane, just as many neutrons enter the upper half core through this surface as leave through it.

The top (and bottom) of the core is assumed to be covered by a layer of water 0.7 meters thick with vacuum beyond (see Figure 7). The water layer is a neutron reflector but not a perfect one. Some of the neutrons scatter off water molecules and return to the fuel but some escape through the surface of the water after several scatterings.

Table A-2 compares $\mathrm{k}_{\text {eff }}$ obtained with MCNP full-core calculations at the beginning and end of design core life with estimates obtained from equation A-1 using $k_{\text {inf }}$ calculated in the infinite core approximation. It will be seen that the differences are typically on the order of 1 percent with the largest difference being about 4 percent. Simplified infinite-core calculations should therefore be adequate for scoping studies such as that presented in this article. 


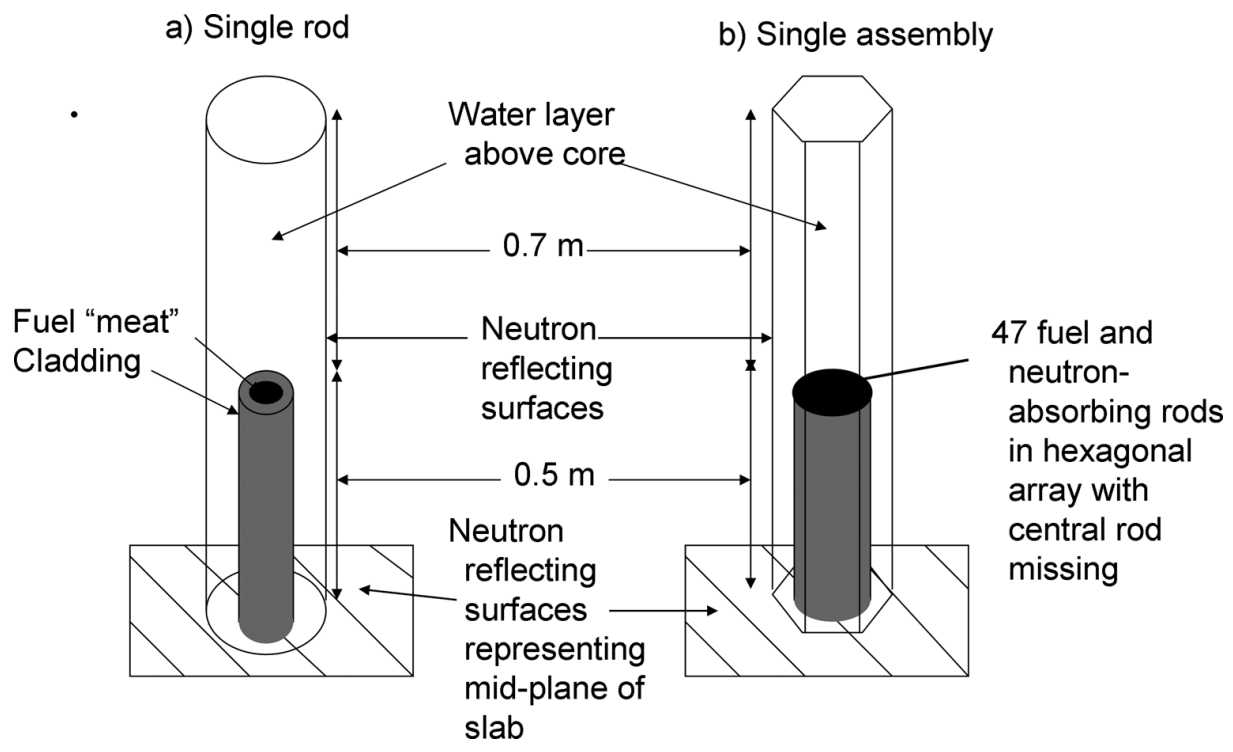

Figure 7: Infinite-slab-core approximation. All of the surfaces surrounding the fuel rod or assembly except the top surface are perfect neutron reflectors. The water surrounding the fuel rod or assembly is assumed to extend above it to a depth of 0.7 meters. Above the water layer there is assumed to be a vacuum. Therefore, neutrons that leave through the top water surface do not return.

\section{NOTES AND REFERENCES}

1. The Reduced Enrichment Research and Test Reactor program. The website for the U.S. RERTR program at Argonne National Laboratory may be found at http://www.rertr.anl.gov.

2. For a discussion of the extent of use of HEU in naval reactors, see, e.g., "Ending the production of highly enriched uranium for naval reactors" by Chunyan Ma and Frank von Hippel, Nonproliferation Review 8 (2001): 86.

3. Sources of radioactive contamination in Murmansk and Arkhangel'sk counties by Thomas Nilsen and Nils Bøhmer (Bellona Foundation, 1994), p. 79.

4. "To equalize the heat-up of the heat transfer agent in various fuel assemblies, the hydraulic profiling is provided which corresponds to the distribution of energy release in the core. The fuel assembly is ... enclosed in a sheathed pipe of zirconium alloy." Information of Safety of Icebreaker... Sevmorput, op. cit., pp. 40-41.

5. "Experience in building and operating reactor systems for civlian ships" by V. I. Makarov, B. G. Pologikh, N. S. Khlopkin, F. M. Mitenkov, Yu. K. Panov, V. I. Polunichev, and O. A. Yakovlev, Atomic Energy 89 (2000), p. 692 (translated from the Russian by Plenum Publishers).

6. Criticality Calculations on Russian Ship Reactors and Spent Nuclear Fuel by M. B. Maerli, S. Børresen, K. Gussgard, and S. Høibråtten, Norwegian Radiation Protection Authority report 1998:7.

7. The Sevmorput safety report gives the temperature coefficient of reactivity as $-5 \times 10^{-4}$ per ${ }^{\circ} \mathrm{C}$, Information of Safety of Icebreaker... Sevmorput, op. cit., p. 42. The Norwegian report estimates a coefficient $40 \%$ as large. 
8. This suggestion was made to us by Alexander Glaser.

9. "Russian nuclear-powered submarine decommissioning" by Oleg Bukharin and Joshua Handler, Science \& Global Security 5 (1995): 245. However, the enrichment zoning described by Bukharin and Handler is of the whole core-presumably to flatten out the initial radial power distribution-with the outer ring being enriched to $43-45$ percent, and the innermost ring being enriched to 21 percent.

10. Calculated assuming 225 fuel assemblies have 48 fuel rods and that the 16 that contain control rods have 36 for a total of 11376 rods or an average of 47.2 per assembly. The total volume of the fuel "meat" is therefore 189 liters.

11. A solid fuel variant is considered briefly in the Norwegian report, Criticality Calculations on Russian Ship Reactors and Spent Nuclear Fuel, op. cit, p. 28-as is the substitution of $20 \%$ and $40 \%$ enriched uranium, ibid, pp. 35-36.

12. "Designing a New Generation Fuel Element for Different Purpose Water Reactors" by A. Vatulin, V. Lysenko, and A. Savchenko, Research Institute for Inorganic Materials, Moscow, Proceedings of the International Meeting on Reduced Enrichment for Research and Test Reactors, Jackson Hole, Wyoming, 5-10 October 1997. The fuel "meat" contains small uranium-containing granules up to $1 \mathrm{~mm}$ in diameter. Two types of granules were considered: (1) porous $\mathrm{UO}_{2}$ imbedded in aluminum alloys (melting temperatures $580^{\circ} \mathrm{C}$ and up) yielding fuel "meats" with densities of 4.6-5.1 gmU/cc; and (2) a uranium alloy (the melting temperature of pure uranium is $1135^{\circ} \mathrm{C}$ ) coated with zirconium (melting temperature $855^{\circ} \mathrm{C}$ ) yielding fuel meats with densities of 9.3-10.9 gmU/cc.

13. We are only aware, however, that this fuel has been tested up to element-average burnups of $60 \mathrm{MWt}$-days/kgU, "Osiris, a MTR adopted and well fitted to LEU utilization, qualification and development" by M. Barnier and J. P. Baylot, Experimental Reactors Department, Saclay, France, Proceedings of the International Meeting on Reduced Enrichment for Research and Test Reactors, JAERI-M 84-073, Tokai, Japan, October 24-27, 1983. The average burnup of the Sevmorput LEU fuel at 417 full-power days would be about 75 MWt-days/kgU.

14. "Designing a New Generation Fuel Element for Different Purpose Water Reactors," op cit. For a fuel element with a radius $0.455 \mathrm{~cm}$ and a surface heat flux of $1.6 \mathrm{MWt} / \mathrm{m}^{2}$, the calculated center-line temperature was $507^{\circ} \mathrm{C}$ for the fuel made with uranium-zirconium alloy granules and $620^{\circ} \mathrm{C}$ for the fuel made with uranium-oxide granules. For a given composition, the center-line temperature is independent of fuelrod diameter for a given linear heat output.

15. A more complete presentation of the assumptions and calculations in the Russian model (in Russian) may be found at http://www.armscontrol.ru/pubs/heu-leureactors.pdf.

16. See, e.g., "The fuel cycle of reactor PIK" by Yu. V. Petrov, A. N. Erykalov and M. S. Onegin, Proceedings of the 2002 International Meeting on Reduced Enrichment for Research and Test Reactors, Bariloche, Argentina, Nov. 3-8, 2002. See also "PIK highflux reactor" by K. A. Konoplev, V. A. Nazarenko, and Y. U. V. Petrov, http://nrd.pnpi. spb.ru/facilities/menu_aboutpik.html, where the pressure of the coolant is given as $5 \mathrm{mpa}$ corresponding to a temperature of about $270^{\circ} \mathrm{C}$.

17. A number of fission products are noble gases. Others-like iodine (boiling point: $184^{\circ} \mathrm{C}$ )—are gases at reactor operating temperatures. Some of these isotopes are quite long-lived (krypton-85, for example, has a halflife of 10.7 years) and accumulate in the fuel. In solid fuels, if there is no porosity or other empty volume into which these gases can flow, they will form bubbles and cause the material to swell. In some materials, the bubbles will join causing a significant probability of fuel failure beyond a certain burnup. 


\section{Diakov et al.}

18. The fuel-rod spacing in Model 1 is larger than the fuel-rod maximum width. Therefore, these fuel rods would require some type of spacer to give the core structural rigidity.

19. The rods are solid gadolinium with a density of $7.89 \mathrm{gm} / \mathrm{cc}$ and $0.27 \mathrm{~cm}$ in radius.

20. Uranium reacts with aluminum to produce $\mathrm{UAl}_{n}$ where $\mathrm{n}=2,3$, 4. If the ratio of aluminum to uranium is greater than 4, the fuel is composed of a mixture of $\mathrm{Al}, \mathrm{UAl}_{3}$ and $\mathrm{UAl}_{4}$. The thermal conductivity decreases linearly with increasing uranium fraction from $2.2 \mathrm{Watts} / \mathrm{cm}^{-}{ }^{\circ} \mathrm{C}$ for pure aluminum to about 0.25 Watts $/ \mathrm{cm}^{-} \mathrm{C}$ for $\mathrm{U}-\mathrm{Al}_{4}$, which has a uranium density of about $3.6 \mathrm{gU} / \mathrm{cc}$, Research reactor core conversion guidebook, Vol. 4: Fuels, Appendix I, "Selected thermal properties and uranium density relations for alloy, aluminide, oxide, and silicide fuels" by J. E. Matos and J. L. Snelgrove, RERTR Program, Argonne National Laboratory, (www.td.anl.gov/Programs/RERTR/FuelProperty/FuelProp.pdf). The highest uranium density for U-Al that has been used in research-reactor fuel is $2.3 \mathrm{~g} / \mathrm{cc}$. Russia has qualified for use in research reactors a $\mathrm{UO}_{2}-\mathrm{Al}$ fuel that has a uranium density of 2.5 $\mathrm{g} / \mathrm{cc}$, "Status and progress of the RERTR program in the year 2003" by Armando Travelli, Proceedings of the 2003 International Meeting on Reduced Enrichment for Research and Test Reactors, Chicago, Ill. October 5-10, 2003, p. 1.

21. According to the Sevmorput safety report, "the compensating ability of five [control rod] banks -25\%," Information of Safety of Icebreaker. . Sevmorput, op. cit., p. 42.

22. Los Alamos National Laboratory, Monte Carlo N-Particle Transport Code System (Radiation Safety Information Computational Center, CCC-660 MCNP4B2 1998).

23. Oak Ridge National Laboratory, ORIGEN 2.1: Isotope Generation and Depletion Code Matrix Exponential Method, (Radiation Safety Information Computational Center CCC-371, 1996).

24. The "meat" of the neutron-absorbing rods is assumed to be a mixture of 0.2292 gadolinium and 0.7708 zirconium by weight with a combined density of $6.83 \mathrm{~g} / \mathrm{cc}$, a radius of $0.23 \mathrm{~cm}$ and zirconium cladding $0.06 \mathrm{~cm}$ thick.

25. We follow here the treatment in Samuel Glasstone and Alexander Sesonske, $\mathrm{Nu}$ clear Reactor Engineering (Van Nostrand Reinhold, 1967), chapter 4.

26. ibid, p. 209.

27. Results derived from the single-assembly infinite-core calculations have been previously presented in "Feasibility of converting Russian icebreaker reactors" by Jungmin Kang and Frank von Hippel, presentation at the Global 2001 International Conference on the Back End of the Fuel Cycle, Paris, Sept. 9-13, 2001. 